\title{
INFORMACIÓN Y BIBLIOTECAS EN TORNO A LOS DERECHOS HUMANOS
}

\author{
Felipe Meneses-Tello \\ Bibliotecário na Universidad \\ Nacional Autónoma de México. \\ E-mail: fmeneses@unam.mx
}

\section{RESUMEN}

El objetivo de este escrito es relacionar las bibliotecas y los recursos de información con el tema político y social de los derechos humanos. El autor afirma que esta relación tiene diferentes puntos de vista que pueden ser analizados. Así que estos derechos fundamentales se observan desde cuatro perspectivas: 1] la literatura en bibliotecología 2] el universo bibliográfico, 3] la práctica bibliotecaria, y 4] las bibliotecas como entidades de derechos humanos. Varios asuntos clave y conceptos son explicados y aclarados. Este artículo delinea y defiende la afirmación de que el acceso a la información es también un derecho humano; que las bibliotecas son instituciones de derechos humanos; que son un importante mecanismo para proteger el derecho a la información en un amplia gama de formas.

Palabras clave: Bibliotecas, Información, Derechos Humanos, Bibliotecología Crítica

\section{INFORMATION AND LIBRARIES AROUND HUMAN RIGHTS}

\section{ABSTRACT}

The goal of this paper is to connect libraries and information resources with the political and social subject of human rights. The author states that this relationship has different point of views that can be analyzed. Thus, these fundamental rights are viewed from four perspectives: 1] Library science literature, 2] The bibliographic universe, 3] Library practice, and 4] Libraries as human rights entities. Several key issues and concepts are explained and clarified. This paper delineates and defends the claim that access to the library is also a human right; that libraries are institutions of human rights; that are an important mechanism for protecting right to information in a broad range of ways. 
Key Words: Libraries, Information, Human Rights, Critical Librarianship

\section{INTRODUCCIÓN}

La disertación entre "información, bibliotecas y derechos humanos" se puede realizar desde diferentes puntos de vista porque la temática en sí, según observamos, presenta varias aristas de análisis y estudio. De manera que es un asunto inter, multi y transdisciplinario. En este sentido el tema de los Derechos Humanos (DH) está presente tanto en las prácticas bibliográficas y bibliotecarias como en la reflexión teórica en bibliotecología y disciplinas afines.

Para efectos del presente discurso, se tratan los siguientes asuntos:

- La literatura en bibliotecología sobre DH

- El universo bibliográfico con respecto a los DH

- La práctica bibliotecaria en torno a los $\mathrm{DH}$

- La biblioteca como entidad de derecho

El problema de los DH en la esfera de la información y las bibliotecas se asocia a puntos de vista críticos; se relaciona así con la "bibliotecología crítica", misma que se concibe como un movimiento internacional de bibliotecarios y trabajadores de la información, quienes consideran que la condición humana y los DH están por encima de otros asuntos profesionales. Esta comunidad crítica se basa en la valoración, el reconocimiento y el respeto de su responsabilidad social que ella expresa y practica en beneficio de la familia humana; comunidad que ha construido su visibilidad e impulso a lo largo de muchas décadas.

Cabe precisar que la praxis de esta bibliotecología se remonta a la década de 1930 en los Estados Unidos, tiempos en que brota el movimiento bibliotecario progresista en ese país (SAMEK, 2001, p. 8; SAMEK, 2007, p. 57). De modo que esta naturaleza de bibliotecología está estrechamente vinculada con el activismo bibliotecario, con los defensores de la cultura bibliotecaria alternativa. Así, según Samek (2007, p. 57), el movimiento bibliotecario crítico incorpora las nociones de biblioteconomía y/o bibliotecología progresista, activista, radical, independiente, alternativa y anarquista, en suma, con una óptica socialmente responsable. Variantes teórico-prácticas que a nuestro juicio podrían ayudar a configurar 
algunos fundamentos tanto de la "bibliotecología social" como de la "bibliotecología política".

Consecuentemente, el ethos de la bibliotecología crítica tiende a desarrollar acción y pensamiento concernientes a los DH, pero con la finalidad de ayudar a cambiar positivamente el mundo porque el día de mañana podría ser demasiado tarde. La filosofía de esta corriente social en el campo de la bibliotecología nos recuerda y reafirma que las bibliotecas son instituciones sociales, políticas y culturales idóneas para generar cambios desde diferentes ángulos y en diversas latitudes. En términos generales, como refiere Samek (2001, p. 115 y 128), ellas son agentes de cambio social. En conformidad con este punto de vista, esta misma autora asevera que "el movimiento de la bibliotecología crítica es, quizás, el mejor ejemplo de cómo un movimiento se manifiesta en el trabajo bibliotecario y de información para el cambio social" (SAMEK, 2007, p. 57). Al respecto Cossette (2009, p. 61) afirma dos ideas ajustadas a este asunto: 1] las bibliotecas pueden ser una poderosa palanca para la transformación social, y 2] el progreso humano exige una democratización de la información que las bibliotecas ayudan a llevar a cabo.

El pensamiento crítico de la bibliotecología en el siglo XXI muestra así su preocupación en virtud que constantemente los DH son erosionados alrededor del mundo. En razón de esto, la filosofía concerniente a la relación "bibliotecología y humanidad", de la que se puede derivar el nexo "bibliotecas y derechos humanos", cobra particular relevancia en el presente siglo dado que:

El [lector] tiene plena libertad en la toma de contacto con el registro cultural de la humanidad para uso de su propia felicidad y la de la comunidad humana. El trabajo de la bibliotecología es verdaderamente un esfuerzo humano, es decir, una actividad de la humanidad para la humanidad, que tiene como fin el bienestar de la humanidad (COSSETTE, 2009, p. 59).

Pensar en torno a las relaciones "bibliotecología y humanidad" y "bibliotecas y derechos humanos", implica analizar como tema innovador esta idea: "las bibliotecas como instituciones de derechos humanos" (MATHIESEN, 2008). Concepción que, a nuestro juicio, se puede enlazar con un planteamiento más general y aceptado, a saber: "las bibliotecas como instituciones sociales", basada esta sugerencia teórica en los nexos "bibliotecología y sociología" y "bibliotecas y 
sociedad". Correlaciones que pueden ser inherentes a la praxis de lo que reconoce como bibliotecología crítica, y en la que es posible reconocer un objetivo primordial: formar bibliotecarios profesionales con un amplio y profundo conocimiento en materia de derechos humanos, pues ellos tienen la elevada responsabilidad social de satisfacer las "necesidades humanas básicas" en el contexto de la sociedad del conocimiento, tales como las necesidades de comunicar, de deliberar y de saber (MATHIESEN, 2013, p. 70-71).

En tiempos de evidente indignación social los responsables de crear, desarrollar y funcionar bibliotecas no pueden vivir indiferentes al descontento del contexto en el que frecuentemente son violentados los DH. En el cuadrante “información, bibliotecas y derechos humanos", el discurso científico de la disciplina (library science) debe construirse con mira crítica y el quehacer cotidiano de los bibliotecarios (librarianship) debe llevarse a cabo con espíritu ético desde una gestión democrática alternativa. Discurso y quehacer que ayuden, teórica y prácticamente, a restaurar la convivencia humana en varias partes del planeta o para que el entendimiento humano no se deteriore a tal punto que amenace la paz de los pueblos.

\section{LA LITERATURA EN BIBLIOTECOLOGÍA SOBRE DERECHOS HUMANOS}

En el campo teórico de la bibliotecología, como se evidencia, no ha pasado inadvertido el problema entre el quehacer bibliotecario y los derechos humanos. En las bases de datos especializadas en torno a esta disciplina también es posible localizar bibliografía referente a la unidad: "información, bibliotecas y derechos humanos". Así, este vínculo se puede distinguir también a través de la literatura en bibliotecología. El objetivo de este rubro es exponer el estado de arte acerca de este nexo conceptual en el terreno del discurso bibliotecológico.

\subsection{La literatura anglosajona}


Así que el fenómeno de los derechos humanos no ha pasado desapercibido entre algunos colegas que cultivan esta disciplina. Sin embargo, observamos que los análisis y estudios publicados a través de artículos y libros datan principalmente de las primeras dos décadas de siglo XXI y los autores y/o las fuentes de estas publicaciones pertenecen a países angloparlantes (KOREN, 2000; GRAHAM, 2001; SAMEK, 2007, 2008b; PHENIX y McCOOK, 2005, 2007; MARET, 2005; BELL, 2006; McCOOK, 2007, 2014; McCOOK y PHENIX, 2006, 2008; MATHIESEN, 2008; STURGES Y GASTINGER, 2010; EDWARDS y EDWARDS, 2010; WILLIAMS, 2010; BUSCHMAN, 2012; MATHIESEN, 2013, 2015; JAEGER, TAYLOR y GORHAM, 2015; LENART y KOSHELEK, 2015). Aunque en este sentido hay algunas excepciones con respecto a ciertos artículos que se publicaron en las postrimerías del siglo XX (MONTGOMERY, 1996; KOREN, 1997; PERKINS, 1997). Este panorama sobre el asunto que nos ocupa se observa con claridad en las recientes investigaciones que realizaron Mathiesen (2015) -trabajo previamente disponible en línea y a ser publicado en una revista de la especialidad- y Jaeger, Taylor y Gorham (2015) referente a ciertos enfoques que distinguen en la literatura entre "bibliotecología, documentación y derechos humanos" o entre "bibliotecas, derechos humanos y justicia social" respectivamente.

Desde el punto de vista monográfico, han sido publicados tres libros que podríamos considerarlos esenciales para el tema en cuestión. El primero es Librarianship and human Rights: a twenty-first century guide de Toni Samek (2007). Se considera esta monografía como la primera que trata esta relevante temática, pues hace conexiones entre la biblioteca del siglo XXI y el trabajo de información en todo el mundo, pero en estrecha relación con la Declaración Universal de los Derechos Humanos (DUDH). El libro tiene como objetivo crear conciencia en torno a los elementos existentes y propuestas de la DUDH que se refieren sobre todo a los valores fundamentales de la institución bibliotecaria, tales como: la información, la ética y la justicia global de la información. Valores ajustados en el contexto de lo que se ha denominado como bibliotecología crítica (Samek, 2007, p. xxiv- xxv). Las reseñas a la obra de Samek han sido publicadas en: Kranich, Nancy. The Library Quarterly. 78 (3) (2008): 343-345; Hannabuss, Stuart. Journal of Librarianship and Information Science. 40 (1) (2008): 59-60.; Hilton Boon, Michele. SHINe Journal. 52 (2007): 14-15. 
El segundo libro es Beyond article 19: libraries and social and cultural rights, editado por Julie Biando Edwards y Stephan P. Edwards (2010), en el que se presenta un conjunto de ensayos sobre biblioteconomía crítica que sugieren explorar las formas en que los bibliotecarios pueden pensar e incorporar aspectos de los derechos humanos en su praxis profesional (práctica y filosofía). Es una obra escrita por y para bibliotecarios, y en la que se analizan las formas en que los derechos culturales pueden tomar parte en la práctica y filosofía bibliotecarias. El propósito de esta colección de escritos es buscar y pensar en los derechos culturales que pueden tener lugar en el campo profesional de la bibliotecología y/o biblioteconomía (EDWARDS, 2010, p. 1-3).

La monografía de más reciente publicación es la que lleva por título Libraries, human rights, and social justice: enabling access and promoting inclusion (JAEGER; TAYLOR; GORHAM, 2015). En este libro los autores exploran la interrelación "información, derechos humanos y justicia social” en el mundo de las bibliotecas. De modo que el contenido del escrito está destinado para orientar al personal que hace funcionar estas instituciones con el fin de que él logre comprender su papel en la promoción de estos derechos desde una perspectiva de justicia social, permitiéndole así el fomento de la igualdad y la equidad, principalmente en poblaciones vulnerables o marginadas. En este sentido, se tratan asuntos relacionados con la alfabetización digital y la inclusión digital, aspectos esenciales a considerar para el suministro de información con respecto a los DH en contextos de justicia social. Todo esto se discute a través de perspectivas jurídicas, políticas, sociales, culturales y económicas con el objetivo de ayudar a los miembros de la comunidad bibliotecaria a entender que su trabajo debe estar estrechamente vinculado con los derechos humanos y la justicia social.

McCook y Phenix en uno de sus artículos citan (2005, p.26) un libro de su autoría que estaba por publicarse bajo el título Universal responsibility, human rights and librarianship. Aunque Amazon lo reporta publicado por Academic Press en 2008, no tiene ejemplares a la venta; en tanto los catálogos de la Library Congress y British Library no lo registran; como tampoco se halla en el sistema bibliotecario de la University of South Florida, entidad académica en la que Kathleen de la Peña McCook es profesora distinguida. Esto sugiere que este libro aún no ha sido publicado. 
Adhiriéndose a la convicción de que las bibliotecas públicas, académicas, escolares y especializadas son instituciones de derechos humanos y justicia social, Ursula Gorham, Natalie Greene Taylor, Paul T. Jaeger editaron el volumen 41 de la connotada publicación Advances in Librarianship, bajo el título: Perspectives on libraries as institutions of human rights and social justice. Así que este volumen, con 19 artículos de investigadores, educadores y profesionales de una amplia gama de campos, es un recurso relevante para el personal bibliotecario que está interesado en los ideales, las actividades y los programas relacionados con la promoción y la protección de los derechos humanos, componente esencial de la justicia social. Desafortunadamente la versión electrónica no está en acceso abierto. Cabe aclarar que este libro colectivo (GORHAM, GREENE y JAEGER, Paul T., 2016) salió a la luz cuando el autor de la presente investigación ya había enviado a evaluar su escrito con el fin de publicarlo.

Con base en lo anterior, Jaeger, Taylor y Gorham (2015, p. 5), reconocen: "Hasta ahora, sólo unos pocos libros que han sido publicados se dedican al tema de las bibliotecas y los derechos humanos o bibliotecas y justicia social". Si tenemos en cuenta que la DUDH se acerca a su septuagésimo aniversario, no cabe duda que la literatura explícita entre bibliotecas y derechos humanos tardó mucho tiempo en comenzar a generarse. Esto se confirma con lo que se expresa en el siguiente rubro.

\subsection{La literatura iberoamericana}

Esto significa que la reflexión teórica y práctica sobre los derechos humanos por parte de la comunidad bibliotecaria y académica en bibliotecología en el mundo iberoamericano casi no se ha interesado por documentar esta problemática. La primera obra monográfica con respecto a este nexo que se publicó en castellano fue: Biblioteconomía y derechos humanos: una guía para el siglo XXI (SAMEK, 2008a), pero la autora es la canadiense Toni Samek, profesora en la School of Library and Information Studies de la University of Alberta. Se trata de una traducción de su obra en inglés pero con una adaptación especial para Hispanoamérica. 
Una segunda obra en nuestro idioma apareció cinco años después, se trata del libro Ética y derechos humanos para bibliotecas y archivos (LÒPEZ y VIVES, 2013). Este libro está estructurado en dos partes. La primera a cargo de Pedro López trata acerca de los Derechos humanos, y contiene cuatro capítulos, a saber: 1] Introducción, concepto y características de los derechos humanos; 2] Evolución histórica de los derechos humanos; 3] Protección de los derechos humanos y 4] Situación actual de los derechos humanos. La segunda referente a la Ética y deontología se debe a la autoría de Joseph Vives i Gracia, misma que contiene el último capítulo: 5] De la ética del bibliotecario-documentalista.

En México cabe mencionar el libro colectivo Bibliotecas y derechos humanos. Se trata de una compilación de 15 ponencias de los conferencistas que se reunieron en el XX Coloquio Internacional de Bibliotecarios, efectuado entre el 2-4 de diciembre de 2013 y teniendo como marco la XXVII de la Feria Internacional del Libro de Guadalajara. De acuerdo con los temas de esos escritos, vale la pena mencionar los siguientes: "El derecho a saber de las personas con discapacidad visual: un punto de vista desde la ceguera", de Jesús Calvillo Reynoso; "Vayan y enseñen a toda la gente. Fundamentos teológicos para la preservación del derecho a saber desde el libro sagrado del judeocristianismo", de Ángel Gabino Gutiérrez Martínez; "La acción de la biblioteca a favor de la libertad de acceso a la información y de expresión y la libertad intelectual: principios de defensa de los derechos humanos para una sociedad más informada", de Helen Ladrón de Guevara; "El acceso a la información, un derecho ciudadano", de Abdelaziz Abid; "La normativa en México sobre acceso a la información: derecho humano y derecho social”, de Diana Castañeda Ponce; "La biblioteca universitaria. Derecho de todos: compartir, respaldar, formar", de Ana María Salazar Vázquez; "El papel de los derechos humanos en la formación de lectores mediante las TIC", de Yolanda Isabel Gayol de Payán; “Uso de la información y de las TIC por indígenas vinculadas con derechos humanos", de Edith Bautista Flores; y "El derecho de acceso a la información pública en México: avances y desafíos", de Moisés Pérez Vega y Diego Alberto Hernández Vázquez. En el discurso inaugural se pronunció el objetivo del evento: “[...] señalar la importancia de la biblioteca en la promoción y defensa de los derechos fundamentales de los ciudadanos, a través del acceso a la información, al conocimiento y a la cultura, contribuyendo a una sociedad igualitaria, 
participativa, informada y democrática [...]" (MORÁN y LÓPEZ, comps., 2014, p. 1314).

Con respecto a las publicaciones en forma de artículos referentes a la disciplina y en nuestro idioma uno de ellos se debe también a Samek (2008c). El único artículo explícito de autoría hispana acerca de esta temática es el de Pedro López, académico de la Universidad Complutense de Madrid, quien sugiere considerar el tópico de los derechos humanos como guía para el trabajo bibliotecario e incluir esta temática en los planes de estudio que se imparten en las escuelas de ciencias de la información, bibliotecología y documentación (LÒPEZ, 2011).

\section{EL UNIVERSO BIBLIOGRÁFICO EN MATERIA DE DERECHOS}

\section{HUMANOS}

Los escritos en torno a la problemática de los derechos humanos en el campo de las ciencias sociales y humanísticas no es reciente (RENTELN, 1988; FELICIANO, 1980). Las publicaciones acerca de esta temática han sido abordadas a partir de diferentes enfoques. Por ejemplo, en los catálogos de importantes sistemas bibliotecarios académicos y especializados encontramos registros bibliográficos de obras desde puntos de vista filosóficos, sociólogos, antropológicos, políticos, jurídicos, históricos, pedagógicos, económicos, teológicos y otros. En relación con esta gran temática y como parte de la diversidad cultural en el mundo de la información impresa y digital, la variedad documental de títulos, autores, editoriales, temas y formatos con respecto a los DH muestra una gran diversidad bibliográfica y documental.

La documentación referente a estudios sobre los "human rights", hasta antes de 1945, tuvo un desenvolvimiento amorfo. Sería a partir del 10 de diciembre de 1948, fecha en que la Asamblea General de la Organización de las Naciones Unidas (ONU) proclama la célebre Declaración Universal de los Derechos Humanos (DUDH), cuando comienza a generarse una gran cantidad y variedad de bibliografía que ha exigido rigurosos análisis académicos, generándose así la “explosión de documentación en derechos humanos” (FELICIANO, 1980, p. 237). 
Una muestra de este fenómeno es la enorme producción documental de las organizaciones no gubernamentales que han venido conformando el movimiento internacional de los derechos humanos al término de la Guerra Fría (MONTGOMERY, 1996, p. 87).

Recordemos que el trabajo bibliográfico tiene como objetivos esenciales los siguientes: 1] permitir el control bibliográfico en bibliotecas y centros de información y documentación, 2] ayudar así a la búsqueda de trabajos publicados en torno a la gran variedad y enfoques con respecto a estos derechos, 3] facilitar y estimular la investigación y redacción de los estudiosos y estudiantes de las ciencias sociales y humanísticas, y 4] apoyar a varios grupos de activistas que batallan en el campo de los DH.

Bajo este rubro es pertinente incluir el quehacer bibliográfico propiamente dicho, es decir, las diferentes bibliografías que han sido elaboradas por organismos y autores nacionales, extranjeros (o de otros países) e internacionales. La bibliografía, como rama de la bibliotecología, aporta recursos documentales organizados de información a través de la serie de repertorios bibliográficos. El servicio de consulta especializada, como parte esencial de un eficaz servicio de documentación, no puede funcionar sin obras secundarias y terciarias de información que faciliten la búsqueda y localización de referencias bibliográficas, organizadas bajo determinado método documental.

Consecuentemente, las obras secundarias de información son parte importante en los acervos de algunas bibliotecas para la gestión del servicio de consulta en materia de DH.

Estas compilaciones de referencias bibliográficas sobre estos derechos han sido publicadas como: 1] bibliografías propiamente dichas, 2] anexos en libros y 3] artículos de revistas (FELICIANO, 1980, p. 239). Podemos observar así que el tema de los derechos de las personas no se ha mantenido al margen de la bibliografía especializada.

En contraste con la literatura en bibliotecología explícita en DH que comienza a emerger en el siglo XXI, el trabajo de bibliografía sobre esta misma temática se origina durante la segunda mitad del siglo XX y continúa en el presente. Por tanto, la bibliografía especializada antecede al discurso bibliotecológico en el campo de los DH. 


\subsection{Bibliografías nacionales}

El término de "nacional" se concibe en contraposición de "extranjero". En este sentido, el concepto de "bibliografía nacional" se refiere a la compilación hecha en México. Es decir, nos referimos a las bibliografías mexicanas; o sea repertorios de autores y editores mexicanos y con referencias predominantemente sobre DH concernientes a este país. A manera de ejemplo tengamos en cuenta algunas obras de consulta publicadas en el contexto nacional de México, como las siguientes: Carranza (2004), CNDH (1992), Ferrer (2007), Hurtado (1998, 2010), cuyos títulos respectivamente son:

- La mujer y la niñez desde la perspectiva de los derechos humanos: una bibliografía especializada.

- Bibliografía general sobre derechos humanos

- Compendio de derechos humanos: textos, prontuario y bibliografía.

- Bibliografía sobre el derecho a la salud y los derechos humanos

- Ensayo bibliográfico de derecho constitucional mexicano y de garantías, amparo y derechos humanos.

Observamos que la temática de los DH en el campo de la bibliografía cobra un alto grado de especificidad. En virtud de los registros bibliográficos que contienen esas obras de referencia, es común que formen parte de bibliotecas institucionales, principalmente especializadas y académicas.

\subsection{Bibliografías extranjeras}

Para México las bibliografías hechas por instituciones de otros países son "bibliografías extranjeras"; y viceversa, para esos otros países las bibliografías mexicanas son de tipo extranjero. Como vemos, el concepto de "bibliografía extranjera" tiene doble sentido y puede complementarse con la noción de 
"bibliografía internacional", pero ambas expresiones no debemos considerarlas como sinónimos. Por esto es menester analizar por separado estas dos categorías.

Naturalmente las bibliografías antes de la aparición del documento electrónico incluían solo referencias de fuentes impresas (GARLING, 1978); a partir del desarrollo de documentos digitales los repertorios bibliográficos comenzaron a incluir obras tanto en forma impresa como en línea (KAHL y DAVISKAHL, 2010); o bien solamente recursos que se localizan en la Internet (CARTER y DAVIDSON, 1997), tales como recopilaciones de sitios web relativos a DH (COWGILL, 1998; HODGSON, 2001). Estos últimos repertorios valorados en el marco de la webibliography.

Bajo este rubro consideremos la Bibliografía seleccionada: derechos humanos y dictadura en Argentina, la cual contiene libros, publicaciones periódicas y recursos electrónicos. Esta aportación ha sido elaborada por la Biblioteca Utopía del Centro Cultural de la Cooperación, disponible en Internet. Otras fuentes de referencia de este tipo se anotan a continuación de manera cronológica:

- Library holdings in London on human rights, censorship and freedom of expression: with select bibliography. Garling (1978)

- Human rights: a topical bibliography. Martin (1983)

- Human rights: an international and comparative law bibliography. Friedman y Sherman (1985)

- Human rights reports: an annotated bibliography of fact-finding missions. Verstappen (1987)

- Learning about rights: a selected bibliography of civil liberties and human rights materials. Dunn (1991)

- Women's international human rights: a bibliography. Cook (1992)

- Human rights and mental health among Latin American women in situations of state-sponsored violence: bibliographic resources. Lykes, Brabeck, Ferns y Radan (1993)

- A selected bibliography of human rights and right to health. Bernier (1994)

- A select bibliography of women's human rights. Cook (1995)

- A selected bibliography of women's health and human rights. Gruskin y Studdert (1995) 
- A selected bibliography of human rights and disability. Hendriks, Neufeldt y Mathieson (1995)

- Human rights in theory and practice: a selected and annotated bibliography. Walters (1995)

- A selected bibliography on current issues in humanitarian action. Vincent (1996)

- Human rights on the Internet: a select bibliography of Web resources. Carter y Davidson (1997)

- A select bibliography on health aspects of human rights (1984-1999). Fluss (2002)

- Bibliography: sexuality and human rights. Fried (2005)

- Human rights reference sources: a critical annotated bibliography. Kahl y Davis-Kahl (2010)

Estas bibliografías varían en relación con el método utilizado por sus autores. Algunas de estas compilaciones son solamente descriptivas (COOK, 1995; FLUSS, 2002); mientras otras son anotadas (BERNIER, 1994; GRUSKIN y STUDDERT, 1995; VINCENT, 1996; VERSTAPPEN, 1987; WALTERS, 1995; FRIED, 2005; KAHL y DAVIS-KAHL, 2010). La organización de los registros bibliográficos a menudo se presenta bajo temas y subtemas inherentes a los $\mathrm{DH}$, indicando a veces el tipo de documento que se trata (FLUSS, 2002). A partir de esta naturaleza de compilaciones, uno se puede percatar de la relevancia que tiene el trabajo bibliográfico en el entorno de un servicio de referencia sobre DH dentro de algunas bibliotecas especializadas y académicas.

\subsection{Bibliografías internacionales}

Los criterios que nos pueden orientar para identificar una bibliografía internacional, son: 1] el título de la compilación, 2] los idiomas y países respecto a las referencias bibliográficas que contiene y 3] los organismos que editan y publican la obra de referencia. Con respecto al título propiamente dicho la bibliografía a veces incluye la palabra "internacional"; las referencias que contienen comúnmente corresponden a publicaciones de varios países e idiomas; y 
las instituciones responsables de la obra son de carácter internacional, aunque no necesariamente. Un claro antecedente concerniente al trabajo bibliográfico internacional lo destaca Feliciano (1980, p. 239) al escribir:

\begin{abstract}
Hay bibliografías sobre los derechos humanos que se publican por separado o anexas a un libro. Dos bibliografías retrospectivas son la Internacional Human Rights: A Bibliography, 1970-1976 (1976) y la Internacional Human Rights Bibliography, 1965-1969 (1976), compiladas por W. Millar y publicadas por el University of Notre Dame Center for the Study of Human Rights. Estos dos materiales listan artículos de revistas y colecciones sobre derechos humanos pero se limitan al inglés. El Centro tiene planes de extender estas bibliografías a 1948, las cuales incluirían también importantes obras en francés, alemán y español. Una breve bibliografía de la Convención Europea sobre Derechos Humanos es la Bibliographie Concernant la Convention Européene des Droits de l' Homme publicada por la Directorate of Human Rights, Secretariat General of the Council of Europe en 1973.
\end{abstract}

En efecto, en torno a estas obras hay que considerar las editadas y/o publicadas por organismos de carácter internacional, de los que emanan importantes bibliografías internacionales en torno a los DH. Un ejemplo es la obra compilada y publicada en cinco volúmenes por las Union Nations (1993), cuyo título es: Human rights bibliography: United Nations documents and publications 1980-1990

Se sabe que aunque los DH es uno de los principales temas del sistema de la Organización de las Naciones Unidas (ONU), obtener acceso a la información y documentación de ese organismo nunca ha sido fácil (WISEBERG, 1997, p. 350). En este sentido, el control bibliográfico referente a las publicaciones oficiales de esa institución internacional puede ser una gran ayuda para mejorar ese acceso. Tengamos en cuenta que la información documental es la base esencial para promover y proteger alrededor del mundo los diversos derechos de las personas. "Si bien la información en sí misma no cambia la realidad política, sí es una condición previa para el cambio y para la toma informada de decisiones", pues mediante mecanismos de organización y control de la información bibliográfica, los "activistas, académicos y documentalistas de derechos humanos se beneficiarán inconmensurablemente por tener un rápido acceso a la documentación oportuna, integral de los derechos humanos de la ONU”, asevera Wiseberg (1997, p. 362). 
Otro ejemplo es la compilación publicada por la United Nations Economic, Scientific and Cultural Organization (UNESCO) y elaborada por Symonides y Volodin (1997), bajo el título Access to human rights documentation: documentation, bibliographies, and data bases on human rights. Esta gran bibliografía, dividida en cinco capítulos, cubre materiales en inglés, francés y español. Una crítica anotada en torno a esta obra la encontramos en Kahl y Davis-Kahl (2010, p. 36).

Cabe mencionar la compilación de Amnesty International (2002) intitulada Publications on health and human rights themes: 1982-1998, la cual es una actualización de la bibliografía publicada por ese organismo en seis ediciones anteriores (1980, 1984, 1987, 1990, 1993 y 1997). La edición correspondiente al año 2002 estuvo a cargo de James Welsh y Doris Bâsler.

\section{LA PRACTICA BIBLIOTECARIA EN RELACIÓN CON LOS DERECHOS HUMANOS}

Para contemplar de manera más integral el universo bibliográfico y documental, resulta oportuno tener presente las bibliotecas especializadas que han sido desarrolladas sobre el tema de los DH. La apreciación de esta distribución bibliotecaria sugiere admitir la relevancia que tienen las actividades y funciones que deben realizar y desempeñar los profesionales de la bibliotecología en un mundo en donde los DH están bajo continúo ataque por parte de diversos grupos sociales y políticos. Las guerras, los golpes de Estado, la exclusión social, el crecimiento de la brecha entre ricos y pobres, la censura y otras lacras sociales generadas dentro del sistema social capitalista son algunos fenómenos que no son cosa del pasado ni problemas menores, como algunos podrían opinar. De tal suerte que los servicios bibliotecarios y de información en la esfera de los DH pueden considerarse como los recursos indispensables para ayudar a educar e informar a las diversas comunidades de usuarios; así como para contribuir a mitigar la ofensa y el dolor entre las víctimas y a castigar a los responsables que cometen violaciones a esos derechos fundamentales. En razón de esto, esta naturaleza de bibliotecas "son parte central de la infraestructura de los derechos humanos y de la justicia social" (JAEGER, TAYLOR, y GORHAM, 2015, p. 109). 
Si aceptamos el desencadenamiento filosófico que estima que la concientización en materia de $\mathrm{DH}$ requiere tanto de educación como de argumentación (BEUCHOT, 2005, p. 53), entonces el servicio de biblioteca especializada en información sobre los DH es un elemento esencial que se convierte en un derecho en sí para la defensa teórica y práctica de lo que invoca la Declaración Universal de los Derechos Humanos y documentos afines. El despliegue de esta defensa desde la reflexión teórica es relevante porque ésta apoya la defensa práctica (BEUCHOT, 2005, p. 56). La base del fundamento argumentativo respecto a los $\mathrm{DH}$, la promoción de la educación y la concientización en torno a tales derechos es la práctica de una serie de actos intelectuales, tales como: la investigación, la lectura crítica y la interpretación de los documentos organizados que se hallan en las bibliotecas especializadas y académicas sobre temas inherentes a la problemática en cuestión. En suma, detrás de la defensa de los DH se encuentra la base de los servicios bibliotecarios y de información especializados en relación con esos derechos.

La gama de esta naturaleza de centros bibliotecarios está vinculada con los sistemas de fomento y defensa de los DH que han sido creados por distintas organizaciones. Estos sistemas BARBA los distingue, de lo general a lo particular, mediante tres esferas o perspectivas, a saber: la internacional, la interamericana y la propia de México (1997, p. 36).

Para explicar el entramado de bibliotecas especializadas y académicas en DH, discurramos el modelo de lo particular a lo general. Así, pensando en la variedad de bibliotecas que existen alrededor del mundo, de acuerdo con sus alcances geográficos y orgánicos que proyectan, estas instituciones de información bibliográfica las podemos categorizar grosso modo en:

- Bibliotecas mexicanas

- Bibliotecas extrajeras

- Bibliotecas internacionales

- Bibliotecas digitales

En efecto, en el entorno electrónico se aprecia una cuarta categoría: bibliotecas digitales. Así, para ilustrar esta estructura bibliográfica especializada y académica, consideremos algunos ejemplos de diferentes partes del mundo. 
Naturalmente existen bibliotecas que sin ser especializadas sobre $\mathrm{DH}$, tienen en sus acervos importantes colecciones referentes a la diversidad de temas que tratan esta materia. Estos acervos, comúnmente de bibliotecas universitarias, complementan el universo bibliotecario con respecto a los $\mathrm{DH}$.

\subsection{Bibliotecas mexicanas}

En esta primera categoría identificamos, desde el punto de vista institucional, bibliotecas de índole nacional, estatal y local. Son bibliotecas que pertenecen a organismos cuyo radio de acción cubren todo el territorio de la República mexicana, o bien tan solo una entidad federativa del país o una ciudad.

Entre las de carácter nacional destacan la Biblioteca de la Comisión Nacional de los Derechos Humanos (CNDH), el Centro de Documentación y Biblioteca del Centro Nacional de Derechos Humanos (CENADEH); y la Biblioteca de la Comisión Mexicana de Defensa y Promoción de los Derechos Humanos (CMDPDH).

Por lo que se refiere a las bibliotecas de naturaleza estatal cabe mencionar las siguientes: la Biblioteca de la Comisión de Defensa de los Derechos Humanos del Estado de Guerrero; la Biblioteca de la Comisión de Derechos Humanos de Coahuila; el Centro de Documentación y Biblioteca de la Comisión de Derechos Humanos del Distrito Federal.

Bibliotecas de esencia local son la Biblioteca Delegacional de Derechos Humanos en el Distrito Federal, ubicada en la Delegación Magdalena Contreras de la ciudad de México; y la Biblioteca "Rigoberto Menchú Tum" con sede en la ciudad de Puebla.

\subsection{Bibliotecas extrajeras}

Entre las instituciones bibliotecarias de otros países tengamos en cuenta, por ejemplo, la Biblioteca de la Comisión de Derechos Humanos de Nueva Zelanda; la Biblioteca de Derechos Humanos de la Universidad de Minnesota; la Biblioteca de la Asociación Ecuménica de Cuyo en ciudad Mendoza, Argentina, la Biblioteca 
del Instituto de Derechos Humanos de la Universidad Complutense de Madrid, España. La Biblioteca Temática de Direitos Humanos del Centro de Formação Cultural Cidade Tiradentes, São Paulo, Brasil.

Sobre este mismo rubro cabe mencionar las colecciones especializadas que se hallan dentro de algunas bibliotecas universitarias, tales como: el Holocaust, Genocide, and Human Rights Center (HGHRC) en la Biblioteca LeRoy V. Good del Monroe Community College de la Universidad Estatal de Nueva York; y la colección en derechos humanos en el Urban Morgan Institute for Human Rights de la Biblioteca Robert S. Marx perteneciente a la Facultad de Derecho de la Universidad de Cincinnati.

\subsection{Bibliotecas internacionales}

Por lo que toca a bibliotecas de organismos internacionales, recordemos las siguientes: la Biblioteca de la Corte Interamericana de Derechos Humanos en San José de Costa Rica; el Centro de Documentación del Instituto Interamericano de Derechos Humanos también con sede en la capital costarricense; la Biblioteca de la Corte Europea de Derechos Humanos, con sede en Estrasburgo, Francia; y la Biblioteca de Educación en Derechos Humanos, perteneciente a Human Rights Education Associates ubicada en Ámsterdam, Holanda.

Todas las bibliotecas especializadas en $\mathrm{DH}$, en virtud de la naturaleza de sus acervos y servicios que prestan a las comunidades de usuarios, tienden a ser consideradas como "bibliotecas jurídicas" que se hallan funcionando en el entramado de ciertos organismos gubernamentales, académicos y no gubernamentales.

\subsection{Bibliotecas digitales}

Como infieren Séller, Sangrad, Word y Kamuronsi (2010, p. 94) "La literatura desde los campos de la ciencia y tecnología de la información a menudo aclama el uso de las tecnologías digitales como una fuerza democratizadora dentro de una sociedad global de la información". La documentación digital sobre DH responde a las necesidades de información de investigadores, activistas, 
educadores y estudiantes, tal como sucede con la University of Minnesota Human Rights Library, pues desde su creación ésta se ha convertido en un recurso documental básico para toda la comunidad interesada en torno a estos derechos. Asimismo, se considera como uno de los mayores sitios electrónicos de documentación sobre derechos humanos en la web, pues proporciona a los usuarios el acceso a miles de documentos en varios idiomas (HOFFMAN, 2001, p. 145).

En efecto, algunas bibliotecas proporcionan información tanto en formatos impresos como digitales, por lo que los conceptos de "biblioteca digital" o "biblioteca virtual", con respecto al tema que nos ocupa, son una alternativa para ampliar el servicio de biblioteca a través de la Internet y así colaborar aún más en la promoción y protección de los derechos humanos. Otros casos son: la Biblioteca Digital del Ministerio de Justicia y Derechos Humanos de Argentina; la Biblioteca Virtual de Dereitos Humanos de la Universidade de São Paulo; la Biblioteca Digital do Centro Latino-Americano em Sexualidade e Direitos Humanos, ubicada en Rio de Janeiro, Brasil; la Biblioteca Virtual de la Secretaria de Direitos Humanos de la Presidência da República (SDH/PR) de este mismo país. A nivel internacional cabe mencionar la Biblioteca Digital del Instituto Interamericano de Derechos Humanos y el proyecto Human Rights Law Network Digital Library, financiado por la Unión Europea.

A través de los acervos digitales que habilitan esas instituciones al servicio de la sociedad, colaboran en la promoción y protección de los principios y valores en materia de los DH. La práctica bibliotecaria en relación con la información impresa se ha estado sumando cada vez más al desarrollo de colecciones y a la gestión de servicios en el entorno de la información digital. Esta última no es simplemente un complemento, es en realidad una llave clave para un mayor acceso a los documentos que requieren los diversos grupos sociales. La relación entre los derechos humanos y la tecnología de la información sugiere pensar incluso en la necesidad de contar hoy en día con una Declaración de Derechos Digitales (MATHIESEN, 2014, p. 2), la cual permita evitar, en la medida de lo posible, la violación de estos derechos fundamentales en los complejos entornos en línea. En este orden de ideas, se concluye que "el derecho a la Internet debe entenderse como parte de un conjunto más amplio de los derechos humanos, el cual incluye el 
derecho a la cultura" (MATHIESEN, 2012, p. 20); a la cultura de la información electrónica que ofrece la Internet.

El caso de la Human Rights Documentation Initiative a cargo del sistema University of Texas Libraries "demuestra cómo una biblioteca universitaria con sus recursos técnicos, experiencia y compromiso permanente sirve como un repositorio confiable de información", para así poder "dirigir la colección, la preservación y los desafíos de la documentación de derechos humanos de origen digital", principalmente de los entornos frágiles de la información que se genera alrededor del mundo a través de las redes de activistas individuales y organizaciones defensoras, de los archivos personales, de videos de teléfonos móviles, de numerosas relaciones interpersonales, y muchos otros (KELLEHER, SANGWAND, WOOD, KAMURONSI, 2010, p. 95-96).

\section{LAS BIBLIOTECAS COMO ENTIDAD DE DERECHO}

En este apartado se piensa en todos los tipos de bibliotecas que se hallan diseminadas en cualquier territorio nacional y no solamente en las especializadas en DH; o solo en las bibliotecas públicas, como sugieren o hacen énfasis algunos autores (McCOOK, 2004; MATHIESEN, 2013). La biblioteca como entidad de derecho humano no únicamente concierne a la "public librarianship" (McCOOK, 2011), sino a la bibliotecología y/o biblioteconomía en general. Más aún, en cuestión del nexo entre "bibliotecas y derechos humanos" es pertinente ir más allá de ciertos artículos que contiene la DUDH (EDWARDS y EDWARDS, 2010) para concebir desde perspectivas globales a la institución bibliotecaria como un derecho íntegramente: 1] social, 2] político, 3] cultural y, en esencia, 4] humano. Desde este amplio punto de vista, concebimos a las bibliotecas como instituciones de bienes y servicios que pueden y deben promover, alrededor del mundo, los derechos humanos y la justicia social. Concepción que aprecian claramente algunos autores (JAEGER, TAYLOR y GORHAM, 2015, p. 51).

El argumento que nos permite aseverar que las bibliotecas son, en un eje tridimensional, un derecho social, político y cultural en el entorno de los DH es que lo político, social y cultural se percibe en las tres generaciones de derechos humanos que identificó el jurista checo Karen Vasak: 1aㅡ derechos civiles y políticos, 
$2^{\text {a }}$ derechos económicos, sociales y culturales y $3^{\text {a }}$ derechos colectivos o de solidaridad (LÓPEZ y VIVES, 2013, p. 33). En razón de esto, es como se concibe que la cumbre de la biblioteca como derecho es que esta institución social se debe explicar y entender como un derecho humano. En el campo de nuestra disciplina teórica (bibliotecología) y práctica (biblioteconomía) esta idea es el culmen de la correlación entre "información, bibliotecas y derechos humanos". Razonemos esta dimensión.

Los hilos conductores, concernientes al pensamiento "la biblioteca como un derecho humano", los podemos basar en los siguientes ideales, principios o postulados:

- "la libertad de pensamiento como derecho humano"

- "la libertad de expresión como derecho humano"

- "la información como un derecho humano"

- "el acceso a la información pública como un derecho humano"

- "la libertad de leer como derecho humano"

- "la alfabetización informacional como un derecho humano"

- "el acceso al servicio de biblioteca como un derecho humano"

Pero es necesario aclarar que este conjunto de creencias con un gran espíritu social y una relevante carga política no son derechos propiamente dichos, pues como asevera MacMillan (1986, p. 285), "los derechos no son ideales, son las condiciones mínimas de la vida humana. Confundir ideales sociales con derechos sirve simplemente para degradar el significado y la fuerza moral del concepto de un derecho". Entonces, desde una arista clásica, ¿cómo se define un derecho humano? Renteln (1988, p. 347) dice que "un derecho humano es un derecho que es universal y en poder de todas las personas".; mientras que Mathiesen (2014, p. 2) asevera que "los derechos humanos son los derechos legales y/o morales que las personas tienen simplemente como personas". En consecuencia, los DH se deben conocer, respetar, proteger y cumplir en beneficio de la dignidad humana de niñas y niños, de mujeres y hombres. Para un mayor razonamiento sobre el concepto de "derechos humanos" se sugiere leer el segundo capítulo del libro de Jaeger, Taylor y Gorham (2015, p. 19-32) referente a la evolución histórica de los conceptos de derechos humanos y justicia social; así como los rubros "Los derechos humanos 
definen" (2013, p. 62-64) y la "Teoría de los derechos humanos" (2015, p. 13071310) de Mathiesen. Esta autora nos dice:

[...] sostengo que hay un caso convincente de que los Estados tienen la obligación de crear y financiar las bibliotecas públicas porque el acceso a una biblioteca pública es un derecho humano. El derecho a una biblioteca pública se deriva del derecho humano a la información. El derecho humano al acceso a la información es un derecho de alta prioridad a una amplia gama de información que el Estado tiene la obligación de proporcionar. Las bibliotecas públicas son probadas instituciones eficaces para garantizar el derecho humano a la información; por lo tanto, hay un derecho humano mediante las bibliotecas públicas (MATHIESEN, 2013, p. 61).

Así, el carácter universal de los DH se asocia a la esencia universal del servicio de biblioteca a la luz de la DUDH, entre otros instrumentos afines, considerados como importantes puntos de referencia en tanto nos pueden ayudar a discernir la relación entre "información, documentación y derechos humanos". Instrumentos como los que menciona Maret (2005, p. 33): El Pacto Internacional de Derechos Civiles y Políticos (1976) y Los Principios de Johannesburgo sobre la Seguridad Nacional, la Libertad de Expresión y el Acceso a la Información (1996). De modo que coincidimos con la siguiente idea: "Los bibliotecarios deben conservar el registro y proporcionar los recursos que las personas necesitarán para comprender los problemas morales y éticos que enfrenta el mundo en el siglo XXI" (McCOOK, 2004, p. 26).

Enraizados y fundamentados los DH en los postulados anteriores, los principales derechos de los seres humanos en nuestro campo teórico-práctico son, de lo general a lo particular, los siguientes:

- "el derecho a la libertad de pensamiento"

- "el derecho a la libertad de expresión"

- "el derecho a la libertad de información"

- "el derecho a la información"

- "el derecho de acceso a la información pública"

- "el derecho a la lectura"

- "el derecho a la alfabetización informacional"

- "el derecho de acceso al servicio de biblioteca" 
En concordancia con esta percepción, podemos estar de acuerdo con el punto de vista que afirma: "Los derechos humanos juegan un papel fundamental en la teoría y en la práctica de los servicios de biblioteca" (KOREN, 1997, p. 57). Esto es así pues uno de los elementos esenciales de los centros bibliotecarios son sus colecciones documentales, cuyo desarrollo de estos acervos debe ser con base también en los diferentes ideales y derechos mencionados. En este sentido, es verdad que "la información tiene un impacto significativo en la vida de las personas"; que "el acceso al conocimiento es fundamental para el desarrollo humano" (McCOOK y PHENIX, 2011, p. 342); que "el derecho a la información es un importante derecho humano" (YILMAZ, 1999, p. 104); por lo que uno de los pilares de la sociedad del conocimiento es "el acceso universal a la información" (FARMER, 2015, p. 21). Por lo tanto, "el derecho a una biblioteca pública se deriva del derecho humano a la información" (MATHIESEN, 2013, p. 61). Conviene aquí pensar un concepto amplio en relación con la noción de "biblioteca pública" con la intención de incluir también a las bibliotecas escolares y académicas como instituciones que pueden ayudar a fomentar y cumplir los derechos humanos, tal como refieren Jaeger, Taylor y Gorham (2015, p. 5). Así, en virtud que todos los tipos de bibliotecas trabajan de diferentes maneras para garantizar el acceso equitativo a las colecciones documentales y el uso en condiciones de igualdad de los servicios al público y recursos tecnológicos, se sugiere que también las bibliotecas especializadas y nacionales figuren como instituciones aptas para este cometido.

Entonces, si el derecho a la información es uno de los principales derechos humanos que protege y desarrolla la vida humana, las bibliotecas se deben concebir con firmeza como un derecho humano social, político y cultural. En este orden de ideas, concordamos en parte con el punto de vista que afirma que la DUDH “deberá ser la estrella polar que guié el servicio de biblioteca pública en el siglo veintiuno" (McCOOK y PHENIX, 2011, p. 339). En parte pues ese documento debe guiar también los servicios de bibliotecas escolares, académicas, especiales, especializadas y nacionales, es decir, todo tipo de centros bibliotecarios que se hallan distribuidos en los diferentes sectores público, social y privado. Con este punto de vista, la idea concerniente a las bibliotecas como entidades de derechos humanos no se confina al concepto tradicional de biblioteca pública que McCook analiza en su Introduction to public librarianship; tampoco se limita al punto de 
vista que sostiene en términos similares Mathiesen (2013, p. 61), autora citada anteriormente.

Las bibliotecas como instituciones y espacios de información es posible visualizarlas como un "derecho humano derivado" que puede y debe amparar los "derechos humanos básicos", pues en efecto hay un derecho humano que dimana, en torno a las bibliotecas públicas, del derecho humano a la información (MATHEISEN, 2013, p. 74). Es decir, "el derecho a buscar y recibir información apoya a un gran número de otros derechos, y en muchos casos el derecho a la información es un componente de otros derechos" (MATHIESEN, 2014, p. 10). Así, los centros bibliotecarios han mostrado ser entidades eficaces para resguardar este derecho fundamental en el marco de la sociedad de la información.

Acorde con lo expresado, la premisa "la biblioteca como un derecho humano", procede hasta cierto punto del análisis concerniente al nexo "bibliotecas, bibliotecarios y derechos humanos", fraguado en la literatura sobre bibliotecología (PERKINS, 1997; McCOOK, 2004; PHENIX y McCOOK, 2005; BELL, 2006; McCOOK y PHENIX, 2006). Todo esto a pesar de que, como reconoce Mathiesen (2013, p. 66) ningún acuerdo internacional de derechos humanos ha considerado el acceso a una biblioteca pública como un derecho humano.

Según Mathiesen (2013, p. 64), los estudiosos en el campo inherente a lo que se denomina como Library and information Science (LIS) han señalado tres conexiones principales entre bibliotecología y derechos humanos, a saber: 1] una ética profesional, 2] una misión para archivos [y bibliotecas] y 3] una justificación con respecto a los servicios bibliotecarios. Recientemente esta autora afirma que en la literatura de la especialidad y campos afines las intersecciones entre "derechos humanos y las preocupaciones centrales de la LIS" se muestran mediante dos enfoques que se complementan entre sí, a saber:

La primera intersección es lo que yo llamo "la informática de los derechos humanos", que se centra en la recopilación, organización y análisis de la información relacionada con los derechos humanos. La segunda es lo que yo llamo los "derechos humanos informativos", que tiene un enfoque de derechos humanos a la ética de la información, centrándose en los derechos humanos relacionados con la recolección de información, organización, acceso y control. (MATHIESEN, 2015, p. 1310). 
Confluencias que en cierta manera coinciden con partes del esquema que venimos tejiendo a través de la presente investigación, en la que fijamos y trazamos el nexo general "información, bibliotecas y derechos humanos". Naturalmente que podemos pensar en otras bifurcaciones para ponderar la relación "derechos humanos y bibliotecología", cruce que nos permita considerar, en efecto, a las bibliotecas como un derecho humano. Profundicemos en los siguientes rubros en otras convergencias, toda vez que se reconoce que "las bibliotecas ya actúan como instituciones de derechos humanos", y que "la literatura profesional está llena de casos y servicios que son actividades de derechos humanos y justicia social, incluso si no son nombrados como tales" (JAEGER, TAYLOR y GORHAM, 2015, p. 67).

\subsection{Las bibliotecas como derecho social}

La idea "la biblioteca es un derecho social" se relaciona con el argumento que propone que la biblioteca es una institución social de servicio a disposición de las personas, del grupo, de la comunidad, del pueblo, de la sociedad y, por ende, regulada por los poderes del Estado. Como tal derecho social, la institución bibliotecaria interesa a todos los grupos sociales, a toda la población rural y urbana, a los gobernados y gobernantes, a los presentes y futuros ciudadanos. Más aún, la biblioteca como institución de servicio en un contexto social (McCABE, 2001, p. 121) para todos toca tanto el interés de las personas en lo particular como el interés de la sociedad en lo general, es decir, este sistema de colecciones, servicios y recursos está comprometido por el bienestar individual y general de todos los miembros que conforman la diversidad cultural de los grupos sociales. Es responsabilidad, por tanto, de todos velar porque sea respetado este derecho social. Es decir:

El papel de la biblioteca como un bien común para la discusión pública requiere una vigilancia constante por parte de los bibliotecarios a fin de salvaguardar este papel. Las bibliotecas públicas proporcionan un lugar [idóneo] donde los miembros de la comunidad pueden reunirse para debatir, realizar investigaciones y convocar para abordar temas de interés local y cometidos más amplios. (McCOOK, 2004, p. 25). 
En la calidad de derecho social, la naturaleza legislativa-jurídica-política de las bibliotecas en México se reconoce que "es de observancia general en toda la República"; asimismo "sus disposiciones son de orden público e interés social" (México. Leyes. Ley General de Bibliotecas). Con base en esta estipulación, corresponde a toda la comunidad de este país velar por la vigencia, el desarrollo y la protección de este derecho. Este carácter legal es posible distinguirlo en todo Estado social de derecho cuyas formas de organización de gobierno son la república y la democracia. Recordemos que la república se funda en el imperio de la ley, en la Constitución como norma suprema y en la legislación federal y local; la democracia se basa en la titularidad del poder del pueblo a través de jornadas electorales, plebiscitos, consultas populares o referéndums. Así que las bibliotecas en los Estados modernos pueden ser consideradas como un derecho social para apuntalar y consolidar una ciudadanía informada y, así, ayudar a generar la participación ciudadana, pues como asevera Mathiesen (2008):

Las bibliotecas proporcionan a las personas información (impresa
y digital), que de otro modo no podrían acceder. Sin bibliotecas
públicas gratuitas, este acceso puede ser bloqueado, ya sea por
barreras económicas, educativas o de otra índole. Para hacer
frente a esto, las bibliotecas deben preocuparse por coleccionar,
además de obras de literatura y materiales de lectura accesibles,
obras con la información necesaria básica en relación con el
contexto. Las bibliotecas también pueden servir como lugares
donde la información pública y gubernamental puede ser
archivada y organizada.

Desde la perspectiva social, se acepta la idea que las bibliotecas deben figurar para servir a los diversos grupos que constituyen la sociedad. De tal suerte que el enfoque social está más ligado con la "sociología", con la teoría de la sociedad del conocimiento y de la información, y con el análisis social de la brecha entre quienes tienen a su alcance más y mejor información bibliográfica, en contraste con aquellas personas que su acceso a este recurso es escaso, cualitativa y cuantitativamente. Empero, la biblioteca como derecho social se asocia a la idea: la biblioteca como edificadora de ciudadanía. Esto implica reconocer a la biblioteca como un derecho democrático, puesto que "la democracia hace que la biblioteca sirva a todos y a cada uno", por ende, esta institución social, "debe servir a todo ciudadano encumbrado o humilde de nacimiento, rico o pobre, poderoso o débil" 
(RATH y RATH, 1993, p. 13). O como se infieren McCook y Phenix (2008, p. 23) al reconocer la importancia de la biblioteca para todos en la sociedad democrática:

Las ideas fundamentales de la biblioteca pública reconocen que una sociedad democrática se basa en una ciudadanía informada y que los ciudadanos educados, a su vez, elegirán legisladores o representantes ilustrados y [así] participar con inteligencia en la toma de decisiones, en los asuntos locales y nacionales de interés común.

La biblioteca, independientemente de su tipo, debe ser reconocida como derecho social porque resulta valiosa para las personas en particular y para la sociedad en general. Las bibliotecas son espacios intelectuales de la comunidad en virtud que a sus miembros y grupos les permiten ampliar y profundizar en el contenido de sus colecciones bibliográficas; enriqueciendo así tanto la vida colectiva como la personalidad individual a través de los servicios bibliotecarios que gestionan estas instituciones para los diversos grupos sociales que atienden. En el caso de los centros bibliotecarios destinados para todos, McCook (2004, p. 25) en otro de sus escritos expresa que "Las bibliotecas públicas proveen a las personas con información vital para que participen en la formación de las políticas públicas y resolver problemas. Tener la oportunidad de mirar todos los lados de los problemas sin temor es un aspecto central de la democracia”. Desde esta arista, la biblioteca como derecho social está sólidamente ligada con la mejora de la democracia como forma de vida; y esto está vinculado también al progreso humano que cultiva y requiere el escenario de la sociedad democrática de la información.

Con base en este razonamiento, concordamos con las puntualizaciones generales de McCook y Phenix (2011, p. 346 y 354): “El acceso al conocimiento, facilitado por los bibliotecarios públicos, es fundamental para el desarrollo humano"; y "el desarrollo de la esta sociedad de la información debe estar basado en el marco de los derechos humanos". Desde estas aristas, el derecho a la libertad de leer se afianza en un doble plano, como derecho democrático y como derecho humano (CHRISTENSEN, 1999); y así sucede con toda la naturaleza de derechos que giran en torno a la relevante relación pensamiento-expresión-informaciónconocimiento-biblioteca. En todo caso, el derecho humano a la información en el escenario del servicio de biblioteca puede aumentar la fortaleza social, política, 
cultural y humana; por ende, la gama de servicios bibliotecarios puede potenciar la fuerza espiritual de los individuos y las comunidades, incluso de las personas y los grupos sociales más pobres (JAIN y SARAF, 2013), entre otros grupos vulnerables como el caso de los inmigrantes indocumentados en el que se sugiere que los bibliotecarios figuren como recios defensores de los derechos humanos de este tipo de personas. En el contexto de los Estados Unidos McCook (2007, p. 51) es categórica al escribir: "Como primera prioridad los bibliotecarios deben mirar hacia adelante para salvaguardar los derechos humanos de los inmigrantes que viven y trabajan entre nosotros". Naturalmente esta idea puede ponerse en práctica en otras latitudes dado que el fenómeno de la inmigración tiene alcances internacionales, nacionales y locales. 0 como se infiere en relación con otros grupos en desventaja en el entorno de ese mismo país: "Hoy en día, las bibliotecas ofrecen servicios especializados para algunas de las poblaciones más vulnerables y aisladas del país, incluyendo a los desamparados, los pobres y los encarcelados" (JAEGER, TAYLOR y GORHAM, 2015, p. 61). En este sentido, las bibliotecas que ayudan a mitigar situaciones difíciles de ciertos grupos humanos, tienden en la práctica a ser responsables socialmente con la compleja gama de los DH. Son bibliotecas comprometidas con la comunidad.

Así, las bibliotecas han sido y son instituciones sociales de mayor bien, de relevante utilidad y de sumo bienestar puesto que pueden y deben servir, directa o indirectamente, a todos los seres humanos que vivimos en sociedad. Si es que el ethos social de la biblioteca es el bien social, la utilidad social y el bienestar social que se le atribuye a ésta en la realización de sus actividades y en el desempeño de sus funciones. La relevancia de las bibliotecas por tanto se puede apreciar por el efecto que ellas producen para alcanzar la felicidad humana, cuyo horizonte axiológico debe ser el dotar de prosperidad a la vida de los seres humanos. De modo que la palabra ethos, en el contexto de las bibliotecas, está relacionada con la ética social que se practica o se debe llevar acabo en la esfera práctica de la ética bibliotecaria. Esta visión refleja la importante dimensión social del bibliotecario público (MENESES, 2014, p. 195-198).

\subsection{Las bibliotecas como derecho político}


Mathiesen (2008) al reflexionar acerca del acceso a la información como derecho humano ha pensado también en las bibliotecas como instituciones de derechos humanos. Desde una arista general este autor se aproxima a considerar implícitamente a la biblioteca como un derecho político al referir el derecho a la información como un derecho de libertad a leer que debe proteger y cumplir el gobierno en beneficio de la ciudadanía. En efecto, se trata de procurar que el servicio de biblioteca se gestione como un problema de Estado, esto es, como derecho político que permita, en tanto política pública, la libertad de acceso efectivo a una gran diversidad de información ciudadana que se halla distribuida en diversos sistemas bibliotecarios.

La biblioteca podemos concebirla también como un derecho político porque se puede entender como una institución de servicio público que está o debe estar en esencia para asistir al "pueblo", elemento fundamental del Estado. El concepto de servicio público es analizado por la teoría del Estado, la administración pública y varias ramas del derecho (constitucional, público, administrativo, municipal). Desde esta perspectiva, la biblioteca, como institución de servicio público a disposición del pueblo (al público) y administrada por el brazo ejecutor del Estado (el gobierno) no puede estar al margen de la teoría general del Estado ni de la teoría de algunas especialidades del derecho. La noción de "pueblo" está vinculada con la ciencia política en general y con la teoría de la democracia en particular porque mediante esta expresión se entiende a la sociedad política organizada en Estado; en materia de práctica bibliotecaria e investigación en bibliotecología, la palabra se articula con dos premisas: el acceso a la información y la libertad de leer. Configurándose así el derecho humano inherente a investigar, recibir y difundir información como derechos democráticos. En razón de esto, la biblioteca vista como derecho político se relaciona con la percepción de la biblioteca como derecho social.

Si el Estado se concibe como una organización política de servicios públicos, el servicio público de biblioteca (sistemas de bibliotecas diseminadas en el sector público) se puede y debe distinguir como un servicio de bien común, aún más, como un servicio de bien público. En esta contextura, el ethos político de las bibliotecas apunta hacia el logro, a través de sus colecciones y servicios, del bien público en su doble aspecto, el individual y el social, es decir, del bien común 
público de todos los seres humanos. En concordancia con este punto de vista, la biblioteca en tanto un bien público es una institución indispensable para el desarrollo, el bienestar y la perfección de la persona y la comunidad; es un bien necesario particular y comunitario; es el espacio público que ofrece una gran diversidad bibliográfica y documental organizada para ejercer con plenitud el derecho de la libertad a leer; así como para forjar la libertad de expresión, oral y escrita, en torno a todos los asuntos de interés público. Esta perspectiva proyecta la relevante dimensión política del bibliotecario público, percepción que no se limita al trabajador de la biblioteca pública tradicional, sino que abarca a todo aquel empleado público de biblioteca que labora en los diversos centros bibliotecarios que se hallan distribuidos en el aparato de la Administración Pública del Estado (MENESES, 2014, 198-203). Asimismo, se asocia a la idea de "cada gran bibliotecario es y debe ser un ciudadano participante y un buen político" (BERRY, 2014). Más aún, el papel de la biblioteca como derecho político se relaciona con la idea que infieren Jaeger, Taylor y Gorham (2015, p. 109): “Facilitar el acceso libre a la información es un acto inherentemente político" y no meramente social.

El pensamiento "las bibliotecas como derecho político" tiene que considerar necesariamente el importante nexo entre "bibliotecas y política", el cual gira en torno a relevantes categorías, tales como, de lo general a lo particular: política cultural, política educativa, política del libro, política de la lectura, política del servicio de biblioteca y otras. Es decir, políticas de Estado y gobierno, en tanto que la palabra política es la actividad que tiene como objetivo esencial el gobernar la acción del Estado en provecho de la sociedad. La biblioteca como institución de política cultural nos guía para reflexionar sobre el siguiente rubro.

\subsection{Las bibliotecas como derecho cultural}

Se puede inferir, naturalmente, que las bibliotecas son también un derecho cultural de los pueblos en tanto ayudan a hacer efectivos los derechos culturales que invoca la DUDH, tal como explica Albarillo (2010, p. 85). Un ángulo de análisis en torno a esta dimensión es el valor de la información como un derecho humano, como colige Farmer (2015). No obstante, este tema es más complejo. 
La perspectiva entre "derecho y cultura" aprecia dos puntos de vista: 1] el derecho de la cultura, y 2] el derecho a la cultura. Es decir: la cultura como objeto del derecho (que atañe a lo legislativo-jurídico) y la cultura como objeto de derecho (que alude a lo justo como facultad y garantía). Así, entre "biblioteca, derecho y cultura", podemos identificar: a] la biblioteca como componente del derecho de la cultura y b] la biblioteca como elemento del derecho a la cultura. El primer enfoque versa acerca del potencial legislativo y de la administración jurídica de la biblioteca; el segundo planteamiento apuntala a la biblioteca como una garantía de derecho cultural. Por lo tanto, este último sentido es el que más nos incumbe en este rubro, si bien la primera delimitación es la base legal para legitimar a la institución bibliotecaria como un efectivo derecho cultural para beneficio de todos los seres humanos.

Por un lado, la biblioteca es un componente del derecho de la cultura porque es asunto de las Constituciones, las leyes, los reglamentos y todo tipo de regulaciones en el marco del Estado de Derecho. Desde esta arista, la biblioteca está inserta en un entramado concerniente al derecho del patrimonio cultural de la nación; está incrustada en un régimen constitucional de la cultura impresa. Se trata, en efecto, de la dimensión jurídica del patrimonio cultural bibliotecario. Por otra parte, la biblioteca es un elemento del derecho a la cultura porque es espacio de garantía en relación con la libertad a leer, el acceso al pluralismo de ideas y el progreso cultural de grupos e individuos. Desde esta óptica, la biblioteca es la institución social que promueve, difunde y permite la entrada al mundo de la cultura en general, poniendo a disposición de todos los interesados su patrimonio bibliográfico y documental. De esta manera, la biblioteca es también una relevante institución cultural.

El tema que nos ocupa está relacionado con el contexto que proyecta las relaciones sociales entre personas y grupos en el marco de culturas diferentes. En razón de esto, la biblioteca es un derecho que debe responder al fenómeno de la diversidad cultural. Asimismo, se trata de reconocer la amplia función cultural que desempeña la biblioteca, función reconocida desde hace mucho tiempo (BUTLER, 1952). De modo que la biblioteca como institución cultural no está al margen del desarrollo cultural de los pueblos. Idea que se vincula con la percepción que sostiene que "la biblioteca como institución social no es un caso aislado de 
desarrollo social" (LANDHEER, 1957, p. 217). En este orden de ideas, el nexo "sociedad y cultura" está estrechamente ligado porque tanto el carácter social como el cultural permiten fundamentar el funcionamiento de la biblioteca como un poderoso servicio público en el contexto multicultural, por ende, como una institución que mediante sus colecciones, recursos tecnológicos y servicios promueve los derechos culturales. Albarillo (2010, p. 98-99) acerca de este asunto asevera que:

[...] la diversidad y la promoción del pluralismo cultural debe ser una parte de nuestra visión de la futura biblioteca y de la biblioteconomía. La biblioteca debe ser vista como una institución social que proporciona espacios en la sociedad donde el diálogo inter e intra-cultural puede tener lugar. [...] Al abrazar los derechos culturales y el pluralismo cultural, las bibliotecas pueden jugar un papel crucial en la construcción de sociedades multiculturales tolerantes ya que proporcionan espacios físicos y virtuales que pueden servir como foro público para el diálogo cultural, el debate y el descubrimiento.

\subsection{Las bibliotecas como derecho humano}

Reconocer a la biblioteca como entidad de derecho humano implica admitir que la institución bibliotecaria es y debe ser considerada, sin cortapisas, como un organismo de derecho social, político y cultural. Mathiesen (2013) es quien refiere, insistamos, que el acceso a una biblioteca pública es un derecho humano porque el derecho a este tipo de biblioteca es derivado del derecho humano a la información. Más aun, esta misma autora piensa en torno a las bibliotecas como instituciones de derechos humanos. Esta idea desafiante se basa en la estrecha relación entre "información y biblioteca" en tanto esta última ella la visualiza "como una institución central que puede asegurar el cumplimiento de los derechos de las personas para acceder a la información y puede favorecer [así] la promoción del compromiso con los derechos humanos en general" (MATHIESEN, 2008). Empero este planteamiento gira particularmente en torno a las bibliotecas públicas, punto de vista que, como hemos planteado anteriormente, se puede y debe expandir a todo el espectro bibliotecario universal en tanto que una de las características de los derechos humanos y las bibliotecas es su respectiva universalidad. Desde este ángulo, concordamos con dos relevantes ideas que 
sostienen Jaeger, Taylor y Gorham: 1] las bibliotecas de todo tipo son realmente las instituciones que avivan los derechos y la justicia en sus comunidades, y 2] las bibliotecas contemporáneas son un arsenal de los derechos humanos y la justicia social. Por esto, estos autores afirman que estas instituciones sociales "tienen que empezar a abogar en términos de sus roles como arsenales de los derechos humanos y la justicia social" (2015, p. 111). Idea que armoniza en cierto modo con la perspectiva histórico-social que valoraría a las bibliotecas públicas de Nueva Inglaterra como arsenales de una cultura democrática, de una democracia humanitaria, contexto en que se distingue la figura del bibliotecario como sujeto humanitario (DITZION, 1947, p. 62 y 107).

Sobre esta argumentación es posible defender una idea más general y explícita: las bibliotecas de todo tipo son un derecho humano porque ellas ayudan a respetar, proteger y cumplir los derechos humanos, siendo considerados estos derechos como de alta prioridad para el respeto de la dignidad de la humanidad. Así, nuestro punto de vista valora a la biblioteca como una entidad básica de derechos humanos, por ende, esta institución no se subordina a la función de acceso a los acervos organizados que contienen el recurso de la información, pues la biblioteca para ser aquilatada como derecho humano es menester apreciarla a través de la gama de actividades y serie de funciones que desempeña y que van, unas y otras, más allá de la función de información. Esta perspectiva es la razón fundamental que relaciona las bibliotecas con los DH. En otras palabras, para que las bibliotecas sirvan como instituciones de derechos humanos:

[...] idealmente deberían ser atendidas por bibliotecarios profesionales. La importancia de los bibliotecarios va más allá de sus habilidades cruciales en la búsqueda y organización de la información. Mediante el empleo de trabajadores de bibliotecas cuyas actividades se rigen por normas profesionales (como se expresa, por ejemplo, en los códigos de ética profesional), creamos una profesión dedicada a la "salud de la información" de los individuos y de la sociedad, al igual que los médicos se dedican a la salud individual y pública. Por lo tanto, los bibliotecarios profesionales tienen y deben servir como defensores importantes para la protección de los derechos de información de las comunidades a las que sirven (MATHIESEN, 2008).

El servicio de biblioteca entre los seres humanos crea el ambiente para que ellos crezcan en la riqueza de sus pensamientos y conocimientos. Por esto, los 
acervos, servicios y recursos que ofrecen las bibliotecas han sido, son y serán decisivos para el desarrollo de la humanidad en general y de cada persona en particular. Las instituciones bibliotecarias al servicio de niñas y niños, de mujeres y hombres, gobernantes y gobernados permiten, directa o indirectamente, la prosperidad de ellas y ellos como seres humanos. Ayudan a combatir el analfabetismo, la ignorancia y otros lastres que padece la familia humana; impulsan la vida intelectual, la creatividad, la innovación, la ciencia, la técnica, el arte y la cultura en todos los niveles de la vida humana, social e individual, pública y privada. Las ideas de Mathiesen (2008) nos ayudan a matizar esto cuando escribe:

Las bibliotecas ayudan a promover la alfabetización dando a las personas acceso a los libros y fomentan una cultura bibliográfica. También pueden impulsar la alfabetización digital proporcionando acceso a las computadoras y otras tecnologías de la información. Por último, mediante la elaboración de una colección de materiales de una amplia gama de la cultura y puntos de vista, las bibliotecas pueden promover tanto la comprensión como la tolerancia.

Según observamos, la esfera de acción del servicio de biblioteca es muy vasta, pues apoya toda actividad humana; y tiene la misión de satisfacer todas las necesidades de la sociedad humana. Por esto, la biblioteca como derecho humano es una base de la educación formal e informal. Sin este servicio de información bibliográfica y documental, los seres humanos no podríamos ejercer con plenitud las libertades públicas que señalan otros documentos, mismos que se suman al conjunto de instrumentos señalados anteriormente en torno al derecho a la información, tales como: El Pacto Internacional de Derechos Económicos, Sociales y Culturales (1966), la Convención Americana de Derechos Humanos (1950) y la Carta Africana sobre Derechos Humanos y de los Pueblos (1981), entre otros que configuran el "sistema universal" y los "sistemas regionales" concernientes al derecho internacional de los derechos humanos (LÓPEZ y VIVES, 2013, p. 85-93). La libertad de expresión, raíz esencial de la libertad de información, es la esencia que proyecta a la biblioteca como un recurso cultural fundamental de derecho humano.

Si toda persona tiene derecho a la libertad de expresión, y si de ésta se desprende la libertad de buscar, recibir y difundir información bibliográfica, las 
bibliotecas son reflejo de las primordiales necesidades humanas, habida cuenta que esas instituciones desarrollan colecciones y gestionan servicios indispensables para el eficaz funcionamiento tanto de la estructura social como de la estructura política, esto es, para la buena marcha de la sociedad y del Estado. Con base en este razonamiento, pensamos que es menester que la biblioteca, como entidad de información organizada, evolucione en consonancia con los cambios sociales, políticos, culturales y tecnológicos; es obligación del Estado que la legislación bibliotecaria de toda nación se perfeccione en sus diferentes niveles.

\section{CONCLUSIÓN}

El nexo entre "información y derechos humanos" se expresa claramente en la DUDH. Desde el punto de vista documental, esta relación es posible apreciarla con el trabajo bibliográfico que emprenden autores personales e institucionales en los niveles locales, nacionales e internacionales. Las bibliografías sobre DH representan así importantes fuentes secundarias de información para los estudiosos y defensores de estos derechos. También son excelentes fuentes de referencia para apuntalar el servicio de consulta en aquellas bibliotecas especializadas y académicas sobre los diversos enfoques de los DH.

La relación entre "bibliotecas y derechos humanos", en el marco de la literatura sobre bibliotecología, se produjo a partir del presente siglo. Como hemos observado, la literatura anglosajona en esta especialidad es la que ha estado destacando; la literatura hispanohablante en este campo apenas ha iniciado su andar. En concordancia con este enfoque, los lectores y usuarios de las instituciones bibliotecarias han adquirido, en la práctica y el discurso, el estatus social de seres humanos. En este orden de ideas, el personal de las bibliotecas debe hacer mucho más que aceptar y compartir los valores políticos y sociales de la democracia, debe actuar también de acuerdo con los DH a través de sus actividades $\mathrm{y}$ funciones, métodos y procesos.

Los DH como tema multidisciplinario de estudio, análisis y enseñanza no se ha mantenido al margen del universo bibliotecario, pues ha producido alrededor del mundo la creación de bibliotecas especializadas en torno a la variedad de estos derechos. De tal manera que en el plano de la diversidad bibliotecaria hallamos 
una gran gama de centros bibliotecarios; o bien grandes colecciones sobre DH en algunas bibliotecas de importantes sistemas dedicados a la academia e investigación. La información bibliográfica entonces no se reduce a la esfera de la bibliografía, sino que se extiende y profundiza en el complejo terreno de los servicios bibliotecarios a disposición de la sociedad.

Es notorio que existe un estrecho vínculo entre 1] las necesidades humanas de información bibliográfica, 2] los derechos humanos de información y 3] la creación, mejora y expansión de los servicios bibliotecarios y de información, como actividades humanas, en sus diferentes niveles institucionales y geopolíticos. Entonces el nexo "información, bibliotecas y derechos humanos" se puede esclarecer así: todas las personas, en su condición de seres humanos, tienen el derecho social, político, cultural y humano de beneficiarse de los indispensables recursos bibliotecarios, con la finalidad superior de satisfacer sus necesidades sociales e individuales de información; necesidades humanas en el más profundo y amplio sentido. La información como recurso humano contenido en libros, revistas, periódicos, entre otros soportes y formatos susceptibles de ser usados a través de una gama de servicios bibliotecarios básicos, especiales y especializados; de servicios con recursos impresos y electrónicos.

La temática tratada nos proyecta una perspectiva en torno a la necesidad de estudiar y analizar (de investigar) el carácter práctico y teórico de la bibliotecología para distinguir con mayor precisión su valor humanístico; su importancia para el bien de la humanidad. De este modo el nexo "bibliotecología y humanidad" infiere que el quehacer bibliotecario se realiza para beneficiar a la familia humana. En consonancia con este principio, podemos formular este otro: el trabajo bibliotecario es ante todo un trabajo humano. Principios que nos orientan para afirmar que la especialidad del bibliotecario profesional es una disciplina social, socialmente humana. Así, el discurso académico bibliotecológico debe continuar girando en este siglo alrededor del género humano con la pretensión de que reine la cordialidad, el respeto y la paz entre las personas y las comunidades; entre los individuos y las naciones. Una prioridad de hoy en día es: el mundo necesita de bibliotecarios profesionales con un alto sentido y conocimiento de derechos humanos; con elevado nivel de responsabilidad social y respeto por estos derechos fundamentales. 
Admitimos que la DUDH, entre otros documentos afines, debe orientar la práctica bibliotecaria alrededor del mundo; que la relación entre "información, bibliotecas y derechos humanos" no tiene que reducirse al quehacer de las bibliotecas públicas, sino que debe abarcar todos los tipos de centros bibliotecarios. Asimismo, el asunto de los derechos humanos, en virtud de su relevancia, es un tema que puede y debe ser tratado en las escuelas de bibliotecología, biblioteconomía y ciencias de la información. Es necesario también que los institutos de investigación sobre estas disciplinas cultiven diversos proyectos correspondientes a dicho nexo, particularmente aquellos que se hallan en América Latina.

\section{REFERENCIAS}

ALBARILLO, Frans. (2010). Cultural rights and language rights in libraries. In Julie Biando Edwads and Stephan P. Edwards, editors. Beyond article 19: libraries and social and cultural rights. Duluth, Minnesota: Library Juice Press. pp. 87-111

AMNESTY INTERNATIONAL. (2002). Publications on health and human rights themes: 1982-1998. Health and Human Rights. 4 (1): 215-264

BARBA CASILLAS, Bonifacio. (1997). Educación para los derechos humanos: los derechos humanos como educación valoral. México: Fondo de Cultura Económica

BELL, Carmine J. (2006). Libraries and human rights education. Catholic Library World. 77 (2): 112-120

BERNIER, Lucie. (1994). A selected bibliography of human rights and right to health. Health and Human Rights. 1 (1): 110-120

BERRY III, John N. (2014) Politics \& Libraries: Every great librarian is a politician. Library Journal. 139 (14): 10

BEUCHOT, Mauricio. (2005). Interculturalidad y derechos humanos. México: Siglo XXI.

BUSCHMAN, John (2012). Information rights, human rights, and political rights: a précis on intellectual and contextual issues for library and information science. Progressive Librarian: Journal for Critical Studies and progressive Politics in Librarianship. (38/39): 17-24

BUTLER, Pierce. (1952). The cultural function of the library. The Library Quarterly. 22, (2): 79-91 
CARRANZA HURTADO, María Eugenia. (2004). La mujer y la niñez desde la perspectiva de los derechos humanos: una bibliografía especializada.

México: Comisión Nacional de los Derechos Humanos, 2004.

CARTER, C. E.; DAVIDSON, R. (1997). Human rights on the Internet: a select bibliography of Web resources. Reference Services Review. 25 (1): 51-60.

CHRISTENSEN, Peter G. (1999). Justifying the freedom to read: from democratic right to human right. Public Library Quarterly. 17 (2): 15-32

CNDH. (1992) Bibliografía general sobre derechos humanos. México: Comisión Nacional de Derechos Humanos, 1992.

COOK, Rebecca J. (1992). Women's international human rights: a bibliography. New York University Journal of International Law and Politics. 24 (2): 857-888

COOK, Rebecca J.; OOSTERVELD, Valerie L. (1995). A Select Bibliography of Women's Human Rights. American University Law Review. 44 (4): 1429-1471

COSSETTE, André. (2009). Humanism and libraries; an essay on the philosophy of librarianship. Duluth, Minnesota.

DITZION, Sidney Herbert. (1947). Arsenals of a democratic culture, a social history of the American public library movement in New England and the middle states from 1850 to 1900. Chicago: American library association.

DUNN, John. (1991). Learning about rights: a selected bibliography of civil liberties and human rights materials. UK: Civil Liberties Trust.

EDWARDS, Julie Biando; EDWARDS, Stephan P. Editors. (2010). Beyond article 19: libraries and social and cultural rights. Duluth, Minnesota: Library Juice Press.

FARMER, Lesley S. J. (2015). Information as a human right. International Journal of Adult Vocational Education and Technology. 6 (1): 18-35

FELICIANO, Myrna S. (1980). Human rights documentation. Philippine Law Journal. 55 (3): 237-245

Libraries. (9) (3): 95-106

FERRER Mac-Gregor, Eduardo; CARBONELL, Miguel. (2012). Compendio de derechos humanos: textos, prontuario y bibliografía. Tercera edición actualizada. México: Porrúa.

FLUSS, Sev S. (2002). A select bibliography on health aspects of human rights (1984-1999). Health and Human Rights. (4)(1):265-276 
FRIED, Susan T. (2005). Bibliography: sexuality and human rights. Health and Human Rights Journal.7 (2): 273-304

FRIEDMAN, Julian R.; SHERMAN, Marc I. (1985). Human rigths: an international and comparative law bibliography. Wesport: Greenwood Press. $868 \mathrm{p}$.

GARLING, Marguerite. (1978). Library holdings in London on human rights, censorship and freedom of expression: with select bibliography. London: Writers and Scholars Educational Trust, 77 p.

GORHAM, Ursula; GREENE, Natalie; JAEGER, Paul T. Eds. (2016). Perspectives on Libraries as Institutions of Human Rights and Social Justice. Advances in Librarianship, volume 41. Table of contents available at: http://www.emeraldinsight.com/doi/book/10.1108/S0065-2830201641

GRAHAM, Patterson Toby. (2001). Public library and the civil rights movement Alabama, 1955-1965. The Library Quarterly. 71 (1): 1-27

GRUSKIN, Sofia; STUDDERT, David. (1995). A selected bibliography of women's health and human rights. Health and Human Rights. 1 (4): 477-497

HENDRIKS, Aart; NEUFELDT, Alfred H.; MATHIESON, Ruth. (1995). A selected bibliography of human rights and disability. Health and Human Rights. 1 (2): 212225

HODGSON, K.(2001). Human rights information sources: databases and the Internet. Legal Information Management. 1 (1): 24-26

HOFFMAN, Marci. (2001). Developing an electronic collection: the University of Minnesota Human Rights Library. Legal Reference Services Quarterly. 19 (3-4): 143155

HURTADO MÀRQUEZ, Eugenio. (2010). Bibliografía sobre el derecho a la salud y los derechos humanos. Derechos Humanos México. Revista del Centro Nacional de Derechos Humanos. 5 (14) 163- 173

(Ed.). (1998). Ensayo bibliográfico de derecho constitucional mexicano y de garantías, amparo y derechos humanos. $2^{\mathrm{a}}$ ed. actualizada. México: UNAM, Instituto de Investigaciones Jurídicas.

JAEGER, Paul T.; TAYLOR, Natalie Greene; GORHAM, Ursula. (2015). Libraries, human rights, and social justice: enabling access and promoting inclusion. Lanham, Maryland: Rowman \& Littlefield Publishers.

JAIN, Vivekanand; SARAF, Sanjiv. (2013). Empowering the poor with right to information and library services. Library Review. 62 (1-2): 47-52. 
KAHL, Chad M; DAVIS-KAHL, Stephanie R. (2010). Human rights reference sources: a critical annotated bibliography. Behavioral \& Social Sciences Librarian. 29 (1): 3264.

KELLEHER, Christian; SANGWAND, T-Kay; WOOD, Kevin; KAMURONSI, Yves. (2010). The Human Rights Documentation Initiative at the University of Texas Libraries. New Review of Information Networking. 15 (2): 94-109

KOREN, Marian. (2000). Children's rights, libraries' potential and the information society. IFLA Journal. 26 (4): 273-279

(1997). The right to information: a human right of children. IFLA Journal. 23 (1): 57-59

LANDHEER, B. (1957). Social functions of libraries. Metuchen, New Jersey: Scarecrow Press.

LENART, Bartlomiej; KOSHELEK, Miranda. (2015). Human Rights and Access to Information. Progressive Librarian: A Journal for Critical Studies and Progressive Politics in Librarianship. (43): 57-66

LÒPEZ LÒPEZ, Pedro. (2011). Los derechos humanos como guía para el quehacer de las bibliotecas. Crítica Bibliotecológica. 4 (1): 9-19. Disponible en: http://eprints.rclis.org/16040/6/cb.vol4.no1.pdf

LÒPEZ LÒPEZ, Pedro; VIVES i GRACIA, Joseph. (2013). Ética y derechos humanos para bibliotecas y archivos. Salamanca, España: Federación Española de Asociaciones de Archiveros, Bibliotecarios, Arqueólogos, Museólogos y Documentalistas.

LYKES, M. Briton; BRABECK, Mary M.; FERNS, Theresa; RADAN, Angela. (1993). Human rights and mental health among Latin American women in situations of state-sponsored violence: bibliographic resources. Psychology Women Quarterly. 17 (4): $525-544$

MacMILLAN, C. Michael. (1986). Social versus political rigths. Canadian Journal of Political Science. 19 (2): 283-304

MARET, Susan L. (2005). "Formats are tool for the quest for truth": HURIDOCS human rights materials for library and human rights workers. Progressive Librarian. 26: 33-39

MARTIN, Paul J. (Editor). (1983). Human rights: a topical bibliography. Prepared by the Center for the Study of Human Rights, Columbia University. Boulder: Westview Press. 299 p.

MATHIESEN, Kay. (2008). Access to information as human right. Social Science Research Network. Available at: http://ssrn.com/abstract=1264666 or http://dx.doi.org/10.2139/ssrn.1264666 
(2015). Human rights as a topic and guide for LIS research and practice. Journal of the Association for Information Science and Technology. 66 (7): 1305-1322

29 (1): 2-18

(2014). Human rights for the digital age. Journal of Mass Media Ethics.

(2013). The human rights to a public library. Journal of Information Ethics. 22 81): 60-79

(2012). The human right to Internet access: a philosophical defense. International Review of Information Ethics. 18 (12): 9-22

McCABE, Ronald B. (2001). Library services in a social context. In Civic librarianship: renewing the social mission of the public library. Lanham: The Scarecrow Press. pp. 121-129

McCOOK, Kathleen de la Peña. (2007). Librarians as advocates for the human rights of immigrants. Progressive Librarian: A Journal for Critical Studies and Progressive Politics in Librarianship. 29: 51-54

---------.. (2014). Librarians as wikipedians: from library history to "librarianship and human rights". Progressive Librarian. (42): 61-81

(2004). The librarian and human rights: protecting discourse against repression. Catholic Library World.75 (1) (Sep 2004): 23-28.

McCOOK, Kathleen de la Peña; PHENIX, Katharine. (2008). Human rigths, democracy, and librarians. En The Portable MLIS: insights from the experts. Westport, Connecticut: Libraries Unlimited. pp. 23-34 (1-2): $57-73$ (2006). Public libraries and human rights. Public Library Quarterly. 25

(2011). The future of public libraries in the twenty-first century: human rights and human capabilities. In Kathleen de la Peña McCook.. Introduction to public librarianship. New York, NY: Neal-Schuman Publishers. $2^{\text {nd }}$ ed. pp. 339360

MENESES TELLO, Felipe. (2014). Las dimensiones social y política del bibliotecario público. En Memoria del Foro Nacional de Profesionales de la Información "Prospectiva de la profesión bibliotecaria: visiones y aproximaciones". México: Escuela Nacional de Biblioteconomía y Archivonomía. pp. 194-207

MONTGOMERY, Bruce R. (1996). Archiving human rights: a paradigm for collection development. Journal of Academic Librarianship. 22 (2): 87-96 
MORÁN GUZMÁN, A. G., LÓPEZ RUELAS, S., comps. (2014). Biblioteca y derechos humanos. Guadalajara, Jalisco: Universidad de Guadalajara. Coordinación de Bibliotecas.

PERKINS, Marck. (1997). China, libraries \& human rights. Focus on International and Comparative Librarianship. 28 (3): 155-165

PHENIX, Khaterine \& McCOOK, Kathleen de la Peña. (2007). A commitment to human rights: Let's honor the qualities of a librarian dedicated to human rights. Information for Social Change. 25: 39-48

(2005). Human rights and librarians. Reference \& User Services Quarterly. 45 (1): 23-26

RATH, Moorttimatee; RATH, Pravakar. (1993). Library as a social institution. In Sociology of librarianship. Delhi: Pratibha Prakashan. pp. 12-18

RENTELN, Alison Dundes. (1988). The concept of human rights. Anthropos. 83 $(4 / 6): 343-364$

SAMEK, Toni (2008a). Biblioteconomía y derechos humanos: una guía para el siglo XXI. Gijón, Asturias: TREA.

(2008b). Finding human rights in library and information work Bilgi

Dünyasi. 9 (2): 527-540

(2001). Freedom and social responsibility in American librarianship, 1967-1974. Jefferson, North Carolina: McFarland.

---------. (2007). Librarianship and human rights: a twenty-first century guide. Oxford, England: Chandos Publishing.

(2008c). Los derechos Humanos en el trabajo bibliotecario. Educación y Biblioteca. Dossier El Compromiso social en el trabajo bibliotecario. (166): 70-76

STURGES, Paul; GASTINGER, Almuth. (2010). Information literacy as a human right. Libri. International Journal of Libraries and Information Services. 60 (3): 195-202

SYMONIDES, Janusz; VOLODIN, Vladimir. (1997). Access to human rights documentation: documentation, bibliographies, and data bases on human rights. $3^{\text {rd }}$ ed. Paris: United Nations Economic, Scientific and Cultural Organization. Available at:

http://unesdoc.unesco.org/images/0011/001114/111427Eo.pdf

UNITED NATIONS LIBRARY. (1993). Human rights bibliography: United Nations documents and publications 1980-1990. New York: United Nations. Compilada por la Biblioteca de las Naciones Unidas. Obra en cinco volúmenes. 
VERSTAPPEN, B. (ed.) (1987). Human rights reports: an annotated bibliography of fact-finding missions, London: Zell, 393 p.

VINCENT, Anne. (1996) A selected bibliography on current issues in humanitarian action. Health and Human Rights.. 2 (1): 151-157

WALTERS, Gregory J. (1995). Human rights in theory and practice: a selected and annotated bibliography. Metuchen, NJ: Scarecrow Press. xxiv, 459 p.

WILLIAMS, Simone. (2010).YES Institute: An Example of Librarians Working with a Human Rights Organization. The Unabashed Librarian. 154: 28-30

WISEBERG, Lauire S. (1997). Access to United Nations human rights documentation. Human Rigths Quarterly. 19 (2): 350-364

YILMAZ, B. (1999). The right to information: is it possible for developing countries?. IFLA Journal. 25.(2): 104-107 